\title{
Aspects of size and geography of an African cyberspace
}

\author{
Williams Nwagwu' \\ Africa Regional Centre for Information Science, Oyo State, Nigeria \\ willieezi@yahoo.com \\ Tolulope Ibitola ${ }^{2}$ \\ Nigerian Veterinary Research Institute, Vom \\ itolu200I@yahoo.com
}

\begin{abstract}
Received: 3 July 2010
Accepted: 30 October 2010

In this study, data on web links collected from 15 African countries, three with the highest Internet penetration in each of North, West, Central, East, and South regions were used to study the number and origins of links to Africa. The sample has a ratio of one Internet user per 12 persons. Altogether, all African countries generated a total of 124,047,702 Web pages and 30,546,967 inlinks to the pages, an average of about 0.25 links per page. But the sample constituted which $28 \%$ of all the countries in the region generated $98,629,700$ pages and $21,272,500$ inlinks, an average of about 0.21 inlinks per page. South Africa ranked highest in web pages and web links per population and also received the highest number of inlinks from other African countries and the G8. However, Kenya linked other African countries more than the others did. Population size does not relate to number of web pages, self-inlinks, and inlinks or penetration, but relates positively with number of Internet users. Among others, a major step in boosting use of Internet resources in Africa will be in developing policies that will encourage African countries to use information developed by other African countries.
\end{abstract}

Keywords: Africa; cyberspace, informetrics; Web links;

\section{Introduction}

Africa is the world's second-largest and second most populous continent after Asia, and covers about 30,22I,532 km land mass, including adjacent islands; it covers $6 \%$ of the earth's total surface area, and $20.4 \%$ of the total land area. With more than 900 million people, Africa accounts for about $14 \%$ of the world's human population. Including all the island groups, the continent consists of 57 countries and 46 other territories. Given this huge mass of human population, it will be adequate to examine the use characteristics of the region regarding the Internet, a single network to which all human beings on earth have chances of membership. Of particular interest in this study is the World Wide Web (WWW), a global hypertext system that provides access to documents and that allows its contents to be interlinked locally and remotely. The WWW is the largest decentralized but interlinked collection of documents and multimedia content that encourages the participation of many authors to publish information through a large number of web sites.

Many studies have addressed national and international web use characteristics in Africa. Boldi; Codenotti; Santini; and Vigna (2002) were the first to initiate web use studies in the continent, with their focus on only nine of the 57 countries. There exist other studies that focus on academic uses of the Web. For instance, Nwagwu and Agarin (2006) studied the academic pages of Nigeria, and found that apart from generally very low web presence, Nigerian universities do not link one another other. Onyancha and Ocholla (2006) and Onyancha and Ocholla (2007) studied the web presence and impact of South African universities as well as comparing performance of South African and Kenyan universities on WWW. Although these studies may be indicative of web use in the countries, they do not give us a sufficient picture of web use characteristics in Africa. An understanding of the structure of web production and use in the region could be complemented by examining the number of web pages produced by the most visible Internet user countries and number of links from African countries as well as the links from developed countries. Extending this understanding to the sub-level domains and in relation to the countries' populations will also improve our understanding of the size and origin of links to Africa.

This challenge is confronted in this study by addressing the following research questions:

i. What is the size of the African web space?

ii. What is the size of the web for top fifteen Internet using countries?

iii. What is the size of the inlinks from G8 countries and China to top Internet using African countries?

iv. What is the Web Impact Factor of the countries' web?

I. Williams E. Nwagwu (PhD) is a lecturer in Information Science at the Africa Regional Centre for Information Science of the University of Ibadan in Nigeria. He specialises in metric aspects of information science.

2. Tolu Ibitola is a systems analyst at the Nigerian Veterinary Research Institute, Vom in Plateau State Nigeria. This paper was developed from his master's thesis carried out in 2008 under the supervision of the first author. 
Why do we need to study national and regional web use of Africa? The Web is a major information medium that has influenced all aspects of human lives. It is a realistic mirror of the ways in which we work, play and socialize, and its beauty is in the complexity of global community participation. However, an asymmetry has been observed by several scholars about the pattern of supply of information to the Internet which favours the rich North (Nwagwu, 2006). National or regional number of Web pages proxies the number of documents produced by a country or region, and linkages to them, to a large extent, proxy the popularity of the documents. Also, the WWW is hypertext-powered, and a link can point to anything, be it personal, local or global, be it draft or highly polished, and this makes the Web a great indicator of number and quality of information supplied to the Internet by countries and regions using the facility. Furthermore, the Web has become an important medium of research and education in many parts of the world. It is widely used as one of the primary means of disseminating research findings (Halliday \& Oppenheim, 200 I; Town, Vickery, Kuras \& Weekes 2002; Goodrum, McCain, Lawrence \& Giles 200I). In the same way, both governments and organizations utilize the Web in their activities. Therefore, a systematic evaluation and analysis of links to the Web pages developed in Africa could help us understand how the Internet serves the general populace as well as government, education and organizational purposes. In addition to understanding the pattern of links among African countries, this study infers from link analysis how much of the information developed by African countries is used by the $\mathrm{G} 8$ countries.

\section{Methodology}

2.1 The study area and research design

This study focuses on Africa, a continent that accounts for about 14\% of the world's human population. Number of Internet users is put at $9.03 \%$ while Internet isd 8.28 (Milliwatts Marketing Group 2008). Generally, access to the Internet in this region is generally very poor and uneven, and this is often believed to be due to poor political leadership which leads to poor resources management with the consequences of low availability of infrastructure and poor utilities supply, among others. There are fifty three countries in the region including all the islands. This study adopted a sample survey design to describe the inlinks to Web pages in selected countries in Africa.

\subsection{Population and sampling}

There are 57 countries in Africa, which we categorized according to the five subregions: Central, East, North, South and West. Internet usage statistics of all the African countries were retrieved from the Milliwatts Marketing Group (2008) - an organisation that maintains global Internet statistics. From this statistics, we obtained the Internet penetration statistics and number of Internet users for each country shown in Table I.

Table I Basic Statistics of African countries

\begin{tabular}{|l|l|l|l|l|l|}
\hline Countries & Region & Penetration & No of Internet users & Total pages & Inlinks \\
\hline Sao Tome and Principe & Central & 14 & 6500 & 5900000 & 3420000 \\
\hline Angola & Central & 8.7 & 700000 & 1470000 & 217000 \\
\hline Congo DR & Central & 0.3 & 180000 & 921000 & 925000 \\
\hline Rwanda & Central & 0.7 & 65000 & 355000 & 81600 \\
\hline Gabon & Central & 5.6 & 81000 & 122000 & 25200 \\
\hline Cameroon & Central & 2.0 & 370000 & 116000 & 107000 \\
\hline Equatorial Guinea & Central & 1.5 & 8000 & 25800 & 2490 \\
\hline Congo & Central & 1.9 & 70000 & 21700 & 11200 \\
\hline Central African Rep. & Central & 0.3 & 13000 & 1370 & 5430 \\
\hline Chad & Central & 0.6 & 60000 & 93 & 1840 \\
\hline Seychelles & East & 35.4 & 29000 & 900000 & 556000 \\
\hline Uganda & East & 2.5 & 750000 & 1660000 & 390000 \\
\hline Kenya & East & 7.5 & 2770300 & 1300000 & 331000 \\
\hline Djibouti & East & 2.2 & 11000 & 508000 & 235000 \\
\hline Tanzania & East & 1.0 & 384300 & 917000 & 185000 \\
\hline Ethiopia & East & 0.2 & 164000 & 417000 & 75300 \\
\hline Burundi & East & 0.7 & 8.6 & 990000 & 172000 \\
\hline Sudan & East & 3500000 & 33500 \\
\hline
\end{tabular}

SA Jnl Libs \& Info Sci 2010, 76(2) 


\begin{tabular}{|c|c|c|c|c|c|}
\hline Countries & Region & Penetration & No of Internet users & Total pages & Inlinks \\
\hline Somalia & East & 0.8 & 94000 & 3 & 4650 \\
\hline Eritrea & East & 2.0 & 100000 & 12000 & 3280 \\
\hline Egypt & North & 7.5 & 6000000 & 4970000 & 934000 \\
\hline Algeria & North & 7.4 & 2460000 & 953000 & 163000 \\
\hline Libya & North & 3.8 & 232000 & 218000 & 133000 \\
\hline Morocco & North & 18.1 & 6100000 & 5620000 & 1380000 \\
\hline Tunisia & North & 15.7 & 1618440 & 2180000 & 373000 \\
\hline Western Sahara & North & $\mathrm{n} / \mathrm{a}$ & $\mathrm{n} / \mathrm{a}$ & 0 & 211 \\
\hline Botswana & South & 3.3 & 60000 & 888000 & 152000 \\
\hline Comoros & South & 3.0 & 21000 & 5150 & 3810 \\
\hline Lesotho & South & 2.4 & 51500 & 165000 & 31800 \\
\hline Madagascar & South & 0.6 & 110000 & 570000 & 106000 \\
\hline Malawi & South & 0.4 & 59000 & 182000 & 47800 \\
\hline Mauritius & South & 24 & 300000 & 2340000 & 716000 \\
\hline Mayotte & South & $\mathrm{n} / \mathrm{a}$ & $\mathrm{n} / \mathrm{a}$ & I & 154 \\
\hline Mozambique & South & 0.9 & 178000 & 548000 & 90900 \\
\hline Namibia & South & 3.9 & 80600 & 1030000 & 219000 \\
\hline Reunion & South & 27.4 & 220000 & 396000 & 159000 \\
\hline Saint Helena & South & 13.3 & 1000 & 1420000 & 747000 \\
\hline South africa & South & 11.6 & 5100000 & 80600000 & 16900000 \\
\hline Swaziland & South & 3.7 & 41600 & 380000 & 68500 \\
\hline Zambia & South & 4.4 & 500000 & 607000 & 119000 \\
\hline Zimbabwe & South & 9.9 & 1200000 & 803000 & 255000 \\
\hline Benin & West & 8.7 & 700000 & 70000 & 35000 \\
\hline Burkina Faso & West & 0.6 & 80,000 & 529000 & 131000 \\
\hline Cape Verde & West & 6.8 & 29000 & 422000 & 63400 \\
\hline Cote D'Ivoire & West & 1.6 & 300000 & 301000 & 86600 \\
\hline Gambia & West & 4.9 & 82300 & 267000 & 58400 \\
\hline Ghana & West & 2.7 & 609000 & 440000 & 107000 \\
\hline Guinea & West & 0.5 & 50000 & 89100 & 12600 \\
\hline Guinea-Bissau & West & 2.5 & 37000 & 485 & 602 \\
\hline Liberia & West & 0.03 & 1000 & 89400 & 28900 \\
\hline Mali & West & 0.7 & 88400 & 166000 & 42200 \\
\hline Mauritania & West & 3.1 & 100000 & 316000 & 62600 \\
\hline Niger & West & 0.3 & 40000 & 85100 & 165000 \\
\hline Nigeria & West & 5.9 & 8000000 & 726000 & 147000 \\
\hline Senegal & West & 5.2 & 650000 & 1570000 & 315000 \\
\hline Sierra Leone & West & 0.2 & 10000 & 89400 & 14300 \\
\hline Togo & West & 5.6 & 320000 & 93400 & 22000 \\
\hline Total & & 4.7 & 44845940 & 124047702 & 30546967 \\
\hline
\end{tabular}

Thereafter, for ease of data management, 3 countries in each region with the highest percentage of Internet penetration were selected, yielding the 15 countries shown in Table 2. 
Table 2 Fifteen countries with highest Internet penetration (Miniwatts Marketing Group 2008)

\begin{tabular}{|l|l|l|l|l|}
\hline Country & Population 2007 & Internet Users 2007 & Penetration (P) & (\%) Users (U) \\
\hline Seychelles & 81895 & 29000 & 35.40 & 0.10 \\
\hline Morocco & 33757175 & 6100000 & 18.10 & 13.80 \\
\hline Tunisia & 10276158 & 1618440 & 15.70 & 3.60 \\
\hline South Africa & 43997828 & 5100000 & 11.60 & 11.50 \\
\hline Zimbabwe & 12311143 & 1220000 & 9.90 & 2.80 \\
\hline Benin & 8078314 & 700000 & 8.70 & 1.60 \\
\hline Sudan & 39379358 & 3500000 & 8.60 & 7.90 \\
\hline Egypt & 80335036 & 6000000 & 7.50 & 13.60 \\
\hline Kenya & 36913721 & 2770300 & 7.50 & 6.30 \\
\hline Cape Verde & 423613 & 29000 & 6.80 & 0.10 \\
\hline Nigeria & 135031164 & 8000000 & 5.92 & 18.10 \\
\hline Gabon & 1454867 & 81000 & 5.60 & 0.20 \\
\hline Zambia & 11477447 & 500000 & 4.40 & 1.10 \\
\hline Cameroon & 18060382 & 370000 & 2.00 & 1.90 \\
\hline Congo & 3800610 & 70000 & 8.28 & 0.80 \\
\hline & $4353787 I I$ & 36087740 & 9.03 \\
\hline
\end{tabular}

\subsection{Data collection}

Data collection was carried out in June, 2008 using AltaVista, a search engine that presents the documents that the search engine expects one would find most relevant at the top of the list (Spink and Jansen 2004). The following syntax linkdomain:.A was used to retrieve all pages that inlink pages within the .A domain. For instance, linkdomain:.ng would retrieve all pages that inlink a page within the .ng (Nigeria) domain. The syntax site: was used to retrieve the number of Web pages indexed per site or domain. To extract the number of external inlinks, the Boolean statement, linkdomain: $A$ NOT site:.A was used to report number of Web pages not under .A domain but that link to .A domain. Another Boolean operator, linkdomain:. A AND site:. $A$, was used to report the number of Web pages under domain $A$ that link to domain $A$

Using this procedure, data was collected from the fifteen selected countries on the number of pages in a country's top level and sub-level domains, number of inlinks within a domain, number of self-inlinks within a domain and population of the country. Given the constraints of establishing the country of origin of sites, we attributed a website to a country if the IP address of that website is assigned to a network physically in that country in addition to checking if the Web site's suffix is the official one assigned to the country. The data was initially tabulated using an Excel spreadsheet and then transferred to the Statistical Package for Social Sciences (SPSS) where descriptive analysis was carried out. Spearman correlation analysis was used to examine the bivariate relationship between pairs of the variables, describing values less than or equal to 0.5 as low and values greater than 0.5 as high.

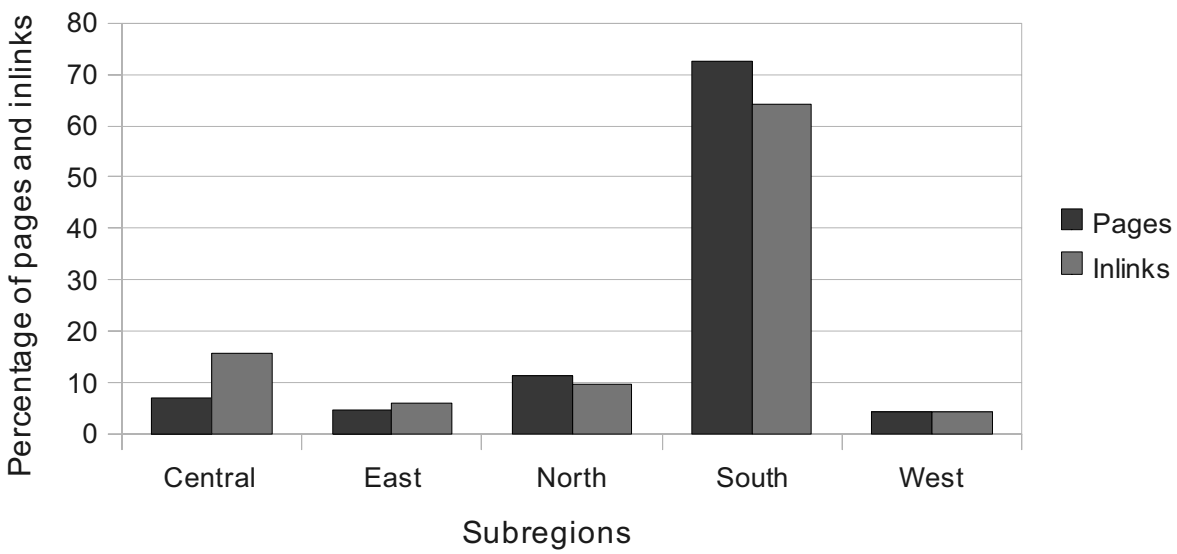

Figure 1 Percentages of pages and inlinks by subregions 


\section{Results}

\subsection{Size of African web space}

\section{I.I Number of Internet users and penetration}

Table I shows that Seychelles has the highest overall Internet penetration figure (35.4), while Liberia has the least (0.03), figures for Western Sahara and Mayotte were not available. Nigeria has the largest number of Internet users while Mayotte recorded only one Internet user. It can be further seen from Table I that African countries generated a total of 124,047,702 web pages and 30,546,967 inlinks to the pages, an average of about 0.25 links per page. In comparison with all the countries, South Africa has the highest number of web pages as well as the highest number of web links while Western Sahara has the least in each case. At the subregional level, Southern Africa subregion has the highest number of both links and pages while the West has the least of both. Southern Africa received I96I5964 inlinks, $64.2 \%$ of the total inlinks received by Africa, Central Africa receives 4796760 (15.7\%), North Africa receives 29832 I I (9.8\%), East receives 1859430 (6.08\%) and West I 291602 (4.2\%).

In the Central subregion, Sao Tome and Principe has the highest penetration figure, the least number of Internet users, the highest number of web pages and inlinks while Central African Republic and Chad have the least penetration figure and number of web pages respectively. Angola has the highest number of Internet users. In the Eastern subregion, Seychelles has the highest penetration figure as well as the highest number of inlinks; the least penetration figure comes from Ethiopia while the least number of inlinks comes from Eritrea. Sudan has the highest number of Internet users, while Djibouti has the least; Uganda is at the top in terms of web pages while Somalia closes the list.

In the Northern subregion, Morocco has the highest penetration figure as well as the highest number of Internet users, web pages and inlinks while Western Sahara has the least penetration, least number of pages and least number of inlinks. In the Southern subregion, the Reunion has the highest penetration figure, while Mayotte trails the list in all the variables. South Africa tops the list in respect of number of Internet users, number of web pages and number inlinks. In West African subregion, the Internet has penetrated Benin more than it has other countries, the least being Liberia. Nigeria ranks topmost in terms of number of Internet users, while the least is also Liberia. Senegal has the highest number of web pages as well as the highest number of inlinks while Guinea Bissau has the least in of inlinks and web pages.

\subsection{Size of the web space of top fifteen countries}

\subsection{Number of Internet users and penetration}

Table 2 shows that the fifteen countries in the study have a total population of 4353787 I I and 36087740 Internet users, a ratio of about one Internet user among every 12 persons. In respect of their individual country populations, Seychelles, Morocco, Tunisia and South Africa have the highest penetration (>10\%), while Congo and Cameroon have the least, 2 or less. But, Nigeria, Morocco, Egypt and South Africa present the highest number of Internet users $(>10 \%)$ while Cape Verde, Seychelles, Congo, Gabon and Zambia have less than one percent number of their populations using the Internet. At the subregional level, the northern sub-region has the highest proportion of Internet users $(10.30 \%)$ while the central has the least $(0.4 \%)$; penetration is highest in the east (17.16) and lowest in the central (3.16).

\subsubsection{Distribution of web pages}

With regards to distribution of web pages, the 15 countries in the study, or $28 \%$ of all the countries in the region, generated 98,629,700 pages and 21,272,500 inlinks, an average of about 0.21 inlinks per page. Further, the sample covered $79.51 \%$ of the total African web pages and $69.64 \%$ of the inlinks. It is very significant that 15 of the 57 countries in the region accounted for about 8 out of every 10 Web pages. Table 3 shows that Southern Africa sub-region leads other sub-regions in the production of Web pages accounting for $83.14 \%$, about five times the number of Web pages contributed by all other sub-regions put together. Within the Southern Africa sub region, South Africa is responsible for over $98 \%$ of the Web pages, while Zimbabwe and Zambia share less than $2 \%$. In the whole sample, South Africa is the highest producer of Web pages in comparison with other countries, generating $80,600,000$ Web pages or $81.72 \%$ of the total number of Web pages produced by the fifteen countries in the region. The Northern Africa sub-region namely Morocco, Egypt and Tunisia contributed $12.97 \%$, with Morocco (5.70\%) leading, followed by Egypt (5.04\%) and Tunisia (2.21\%). The three countries in the East African sub-region contributed only $2.40 \%$ of the Web pages: Kenya accounted for $1.318 \%$, with Seychelles and Sudan making less than significant inputs $(0.913 \%$ and $0.17 \%)$ each. Although Nigeria leads the rest of West African countries in terms of number Web pages produced, it contributed only $0.736 \%$ of the total web pages to the $1.281 \%$ made by the West Africa sub-region. The Central African countries contributed $0.264 \%$, with Gabon leading; Cameroon (0.1 I $8 \%$ ) while Congo (0.022\%) ranked the least in the number of web pages both at the sub-regional and national levels. 
At the sltd level, there were 6,40I, 162 pages in the .org, .gov and .edu sub-domains. The frequency distribution of the pages by sub-domains showed that $40.07 \%$ was organizational, $33.43 \%$ was educational while $26.50 \%$ was governmental pages.

Table 3 Distribution of the Web pages by countries (\%)

\begin{tabular}{|l|l|l|l|l|}
\hline Country & Total pages & .edu & .gov & .org \\
\hline Benin & 0.07 & 0.00 & 0.22 & 0.01 \\
\hline Cameroon & 0.12 & 0.00 & 0.33 & 0.00 \\
\hline Cape Verde & 0.43 & 0.02 & 0.05 & 0.00 \\
\hline Congo & 0.02 & 0.02 & 0.00 & 0.02 \\
\hline Egypt & 5.04 & 8.27 & 17.63 & 19.69 \\
\hline Gabon & 0.12 & 0.00 & 0.06 & 0.00 \\
\hline Kenya & 1.32 & 1.76 & 2.02 & 1.29 \\
\hline Morocco & 5.70 & 3.67 & 7.13 & 1.63 \\
\hline Nigeria & 0.74 & 1.32 & 2.77 & 0.72 \\
\hline Seychelles & 0.91 & 0.01 & 0.11 & 0.00 \\
\hline South Africa & 81.72 & 83.77 & 66.03 & 74.07 \\
\hline Sudan & 0.17 & 0.10 & 1.39 & 0.03 \\
\hline Tunisia & 2.21 & 0.00 & 2.11 & 1.60 \\
\hline Zambia & 0.62 & 0.02 & 0.00 & 0.00 \\
\hline Zimbabwe & 0.81 & 1.03 & 0.16 & 0.95 \\
\hline
\end{tabular}

Africa has the highest educational (83.77\%), governmental (66.03\%) and organizational (74.07\%) web pages. Except Egypt which has $8.27 \%$ of educational, $17.63 \%$ of governmental and $19.69 \%$ of organisational web pages, most of the countries had less than $10 \%$ of links to their educational, governmental and organizational web pages. Congo and Zambia have zero links to their governmental pages; the web pages of Gabon, Benin, Cameroon and Tunisia did not receive any links just as Gabon, Cameroon, Seychelles, Zambia and Cape Verde have no links to their web pages.

\subsubsection{Distribution of web pages per population}

The study attempted to gain an understanding of the number of web pages that could be attributed to an individual in the region by constructing the ratios of web page per population. Generally, at the regional level, an African accounts for 0.28 web pages each. By sub-regions, Table 4 shows that Southern Africa has the highest number of Web pages. The east has the highest educational pages per population as well as the highest number of organizational pages per population. North Africa followed South Africa in terms of the magnitude of total Web pages, inlinks Web pages, organizational, government and educational Web pages. West Africa ranked third in terms of total web pages, but it has higher number of organisational pages per population than the North. The Central sub-region is the least in all terms, and has almost a zero number of government Web pages per population.

By country Table 4 shows further that South Africa continues to lead in terms of the total Web pages, inlinks, educational, organizational and governmental Web pages per population. Morocco, Egypt and Tunisia, all North African countries followed in terms of total number of Web pages per population although the difference with South Africa figure is very high. In terms of inlinks, Seychelles ranked next to South Africa whereas Egypt followed South Africa in terms of Web pages found.

Still on per population statistics, and respecting the sub-level domains, educational pages per population are generally very low. However, South Africa still outranked all other countries in Africa, having 2II educational pages per person. Apart from Egypt and Morocco which have more than unit number of educational pages per person in their populations, Gabon, Benin, Cameroon and Tunisia have zero educational pages while the others have fractional number of Web pages. Although the pattern of proportion of government pages per population follows same trend across the region, these indices appear by far much lower than others. The highest government pages per person could be observed in South Africa which however has as negligible as about 4000 persons for one government web page. South Africa still has higher ratio 
of organizational than educational and government pages per population; organizational population page ratio in Egypt and Morocco followed; but Zambia, Gabon and Cape Verde have zero organizational Web pages per population.

Table 4 Web pages per population (\%)

\begin{tabular}{|l|l|l|l|l|}
\hline Country & Total Web pages & .edu & .gov & .org \\
\hline Benin & 0.01 & 0.00 & 0.01 & 0.04 \\
\hline Cameroon & 1.44 & 0.00 & 0.00 & 0.01 \\
\hline Cape Verde & 5.22 & 0.01 & 0.01 & 0.01 \\
\hline Congo & 0.27 & 0.01 & 0.00 & 0.13 \\
\hline Egypt & 61.52 & 3.38 & 0.01 & 134.67 \\
\hline Gabon & 1.51 & 0.01 & 0.01 & 0.00 \\
\hline Kenya & 16.09 & 0.72 & 0.01 & 8.83 \\
\hline Morocco & 69.57 & 1.50 & 0.01 & 11.17 \\
\hline Nigeria & 8.99 & 0.54 & 0.00 & 4.91 \\
\hline Seychelles & 11.14 & 0.01 & 0.02 & 0.01 \\
\hline South Africa & 997.73 & 34.21 & 0.03 & 506.67 \\
\hline Sudan & 2.129 & 0.04 & 0.01 & 0.18 \\
\hline Tunisia & 26.99 & 0.00 & 0.01 & 10.93 \\
\hline Zambia & 7.51 & 0.01 & 0.00 & 0.00 \\
\hline Zimbabwe & 9.94 & 0.42 & 0.00 & 6.48 \\
\hline
\end{tabular}

\subsubsection{Distribution of inlinks}

The distribution of inlinks to African countries' web pages was also investigated and shown Table 5. The fifteen countries in the sample received a total of 21272500 inlinks. By sub-regions, Southern Africa received $81.20 \%$ of the total inlinks, Central Africa (I5.70\%), North Africa (9.8\%), Eastern sub-region (6.08\%) and West (4.20\%). By country, South Africa also leads in the number of inlinks, compared to any other country, receiving $79.85 \%$ of the total 21272500 inlinks to Africa. This figure is three times higher than the number of inlinks received by all other African countries added together. Apart from Morocco $(6.487 \%)$ and Egypt (4.39\%), Seychelles (2.61\%), Tunisia (I.75\%), Kenya (I.56\%) and Zimbabwe ( $1.20 \%)$, the rest of the countries received less than one percent of the total inlinks to Africa.

Table 5 Distribution of inlinks by countries (\%)

\begin{tabular}{|c|c|c|c|c|}
\hline Country & Inlinks & .edu & .gov & org \\
\hline Benin & 0.08 & 0.00 & 0.71 & 0.01 \\
\hline Cameroon & 0.11 & 0.01 & 0.24 & 0.00 \\
\hline Cape Verde & 0.39 & 0.02 & 0.05 & 0.00 \\
\hline Congo & 0.04 & 0.00 & 0.01 & 0.00 \\
\hline Egypt & 4.50 & 3.44 & 14.50 & 19.07 \\
\hline Gabon & 0.12 & 0.00 & 0.06 & 0.00 \\
\hline Kenya & 1.33 & 1.32 & 3.00 & 1.50 \\
\hline Morocco & 5.95 & 0.00 & 7.70 & 2.71 \\
\hline Nigeria & 0.79 & 1.23 & 2.79 & 0.24 \\
\hline Seychelles & 0.74 & 0.03 & 0.23 & 0.01 \\
\hline South Africa & 82.14 & 93.47 & 65.81 & 73.01 \\
\hline Sudan & 0.19 & 0.10 & 0.98 & 0.01 \\
\hline Tunisia & 2.20 & 0.00 & 1.28 & 1.72 \\
\hline Zambia & 0.60 & 0.04 & 1.24 & 0.74 \\
\hline Zimbabwe & 0.82 & 0.34 & I.4I & 0.97 \\
\hline
\end{tabular}


South Africa (82.14\%) also received the highest proportion inlinks to Africa.

Of the inlinks received by the fifteen African countries, 6511625 (75.00\%) of the inlinks were distributed to sltd as follows: organizational $41.85 \%$, governmental $(27.53 \%)$ and educational $(30.60 \%)$. Inlinks to South African educational pages (93.47\%) were almost 100 times that of any other country except Egypt (3.44\%), its governmental pages $(65.81 \%)$ and organizational pages (73.01\%) were followed by Egypt (14.50\% and 19.07\%). Benin, Congo, Morocco and Tunisia have zero educational inlinks and Cameroon, Cape Verde and Congo also have zero government inlinks.

\subsubsection{Distribution of inlinks per population}

Seychelles has the largest number of percentage of number inlinks per person in comparison with other countries.

Table 6 Inlinks per population

\begin{tabular}{|l|l|}
\hline Country & Inlinks per population \\
\hline Benin & 0.01 \\
\hline Cameroon & 0.02 \\
\hline Cape Verde & 0.14 \\
\hline Congo & 0.01 \\
\hline Egypt & 0.01 \\
\hline Gabon & 0.02 \\
\hline Kenya & 0.01 \\
\hline Morocco & 0.04 \\
\hline Nigeria & 0.01 \\
\hline Seychelles & 6.76 \\
\hline South Africa & 0.17 \\
\hline Sudan & 0.01 \\
\hline Tunisia & 0.04 \\
\hline Zambia & 0.01 \\
\hline Zimbabwe & 0.02 \\
\hline
\end{tabular}

The rest of the countries have fractional percentage of inlinks per population.

Table 7 The distribution of self links in the selected countries

\begin{tabular}{|l|l|l|l|l|}
\hline Country & Total & Education & Government & Organisation \\
\hline Benin & 6760 & 375 & 452 & $\mathrm{I}$ \\
\hline Cameroon & 9300 & 0 & 9,851 & 51 \\
\hline Cape Verde & 33600 & 0 & 1,040 & 0 \\
\hline Congo & 3600 & 12700 & 12,100 & 2250 \\
\hline Egypt & 390000 & 339 & 14,120 & 9300 \\
\hline Gabon & 10400 & 2 & 6 & 0 \\
\hline Kenya & 115000 & 0 & 15,465 & 25904 \\
\hline Morocco & 516000 & 2490 & 2,400 & 10000 \\
\hline Nigeria & 68,700 & 180 & 3,110 & 29 \\
\hline Seychelles & 64100 & 670 & 10,960 & 81 \\
\hline South Africa & 7120000 & 1543890 & 1026000 & 997000 \\
\hline Sudan & 16100 & 2 & 2,030 & 11 \\
\hline Tunisia & 191000 & 72 & 78,000 & 42,800 \\
\hline Zambia & 52000 & 13,800 & 23,200 & 12,901 \\
\hline Zimbabwe & 71400 & 36,600 & 145,000 & 284,000 \\
\hline Total & 8667960 & 1611120 & 1343734 & 1384328 \\
\hline
\end{tabular}


Egypt has the highest inlinks to itd domains while Congo has the least. Table $X X$ shows that there are 8667960. the sld constituted a total of $X X X$ self-inlinks with education accounting for $18.6 \%$, organisational 15.9 ad government $15.5 \%$.

\section{Distribution of self-inlinks and external inlinks among the African countries}

We constructed a matrix to understand the nature inlinks amongst the 15 countries. The result is shown in Table 8 . Reading the table from rows to columns, the figures at the intersections signify the number of external inlinks from countries of origin of the external inlinks (rows) to the countries of destination of the external inlinks (columns). The figures in the diagonal represent the total number of self-inlinks received by the countries, with the indication that the fifteen countries created a total of $8,667,960$ self-inlinks.

Table 8 Distribution of self-inlinks among African countries

\begin{tabular}{|c|c|c|c|c|c|c|c|c|c|c|c|c|c|c|c|c|}
\hline COUNTRY &. $\mathbf{n g}$ &.$c v$ &.$b j$ &.$c g$ &.$c m$ &.$g a$ &.$k e$ &.$s d$ &.$s c$ &.$e g$ & .tn &.$m a$ &.$z m$ &.$z w$ &.$z a$ & Total \\
\hline ng & 68700 & 0 & $I$ & $I$ & 0 & 0 & 13 & 1 & 2 & 5 & 0 & 9 & 2 & 1 & 180 & 215 \\
\hline.$c v$ & 2 & 33600 & 0 & 0 & 0 & 0 & 0 & 0 & 0 & 1 & 0 & 0 & 0 & 0 & 27 & 30 \\
\hline .bj & 1 & 0 & 6760 & 4 & 4 & 1 & 1 & 0 & 0 & 0 & 0 & 1 & 0 & 0 & 123 & 135 \\
\hline.$c g$ & 1 & 0 & 2 & 3600 & 4 & 0 & 2 & 0 & I & 2 & 0 & 8 & 1 & 1 & 16 & 38 \\
\hline.$c m$ & 1 & 0 & 2 & 5 & 9300 & 0 & 2 & 0 & 0 & 1 & 8 & 31 & 2 & 0 & 54 & 106 \\
\hline ga & 2 & 0 & 0 & 1 & 0 & 10400 & 0 & 0 & 0 & 1 & 0 & 10 & 0 & 0 & 73 & 87 \\
\hline ke & 11 & 1 & 1 & 1 & 0 & 0 & 115000 & 3 & 9 & 10 & 1 & 13 & 136 & 15 & 20200 & 20401 \\
\hline.$s \mathrm{~d}$ & 2 & 0 & 0 & 0 & 0 & 0 & 1 & 16100 & 0 & 13 & 0 & 3 & 0 & 0 & 131 & 150 \\
\hline.$s c$ & 4 & 0 & 0 & 1 & 0 & 0 & 4 & 2 & 64100 & 2 & 0 & 23 & I & 2 & 89 & 128 \\
\hline .eg & 3 & 0 & 0 & 2 & I & 0 & 8 & 8 & 4 & 390000 & 49 & 234 & I & I & 850 & 1161 \\
\hline .tn & 4 & 3 & 0 & 4 & 1 & 16 & 1 & 2 & 0 & 121 & 191000 & 293 & 1 & 2 & 58 & 506 \\
\hline ma & 8 & 5 & 2 & 11 & 1 & 13 & 9 & 4 & 13 & 149 & 466 & 516000 & 2 & 2 & 344 & 1029 \\
\hline. $\mathrm{zm}$ & 3 & 0 & 0 & 1 & 0 & 0 & 22 & 3 & 2 & 2 & 2 & 9 & 52000 & 116 & 857 & 1017 \\
\hline. $\mathrm{zw}$ & 2 & 0 & 0 & 1 & 0 & 0 & 20 & 1 & 9 & 2 & 1 & 8 & 192 & 71400 & 2860 & 3096 \\
\hline $\mathrm{za}$ & 59 & 7 & 6 & 9 & 1 & 0 & 538 & 8 & 138 & 239 & 24 & 199 & 482 & 3290 & 7120000 & 5000 \\
\hline Total & 103 & 16 & 14 & 41 & 12 & 30 & 621 & 32 & 178 & 548 & 551 & $84 I$ & 820 & 3430 & 25862 & 33099 \\
\hline
\end{tabular}

Key: $. n g=$ Nigeria, $. c v=$ Cape Verde, $. b j=$ Benin, $. c g=$ Congo, $. c m=$ Cameroon, $. g a=$ Gabon, $. k e=$ Kenya, $. s d=$ Sudan, $. s c=$ Seychelles,. eg $=$ Egypt, $. T n=$ Tunisia, $. m a=$ Morocco, $. z m=$ Zambia, $. z w=$ Zimbabwe, $. z a=$ South Africa

South Africa has the highest number of external inlinks (25862) from all other African countries in the study. It is inlinked by Kenya the most (20200 links) and by Congo the least (16 links). Zimbabwe has the next highest number of external inlinks (3430) from other African countries, inlinked mainly by South Africa (3290) and itself (116) and Kenya (15), but having no inlinks from Cape Verde, Benin, Sudan, Cameroon and Gabon. It received two or less inlinks from the other countries. In terms of total number of links, Kenya, with 2040I links, has the highest number of inlinks to other African countries more than any other African country, followed by South Africa (5000 links), Zimbabwe (3096), Egypt (II6I), Morocco (1029) and Zambia (1017) while Cape Verde, Congo and Gabon sought for information from other African countries the least. However, over $99 \%$ of Kenya's links were to South Africa, while making zero links to Cameroon, Gabon and Zambia. In terms of consistency of links to all the countries in Africa, Morocco made at least one link to each of the Africa countries in the study although its total number of links is less than that of Kenya. Nigeria and South Africa are the only countries that received at least a single inlink from each of the countries; although Nigeria's inlinking magnitude is by far less than that of South Africa. Morocco was inlinked by all except Cape Verde. Cameroon (I2) received the least number of inlinks from other countries while Cape Verde (30) made the least number inlinks to other countries.

\section{External links from the $\mathbf{G 8}$ to Africa}

The G8 countries and China altogether created 10, I4I,734 inlinks to Africa. Table 9 shows that the United States has the highest percentage of links to Africa, followed by UK, Germany, Canada and Italy. The last four countries Russia, France, Japan, and China have very low number of links, which probably mirror the order of relationship that these countries have with Africa in comparison with the other countries. China had the lowest percentage of inlinks to the region, but has its highest linkage to Sudan, a country it recently shares so much in respect of oil exploration and other investments. 
Table 9 External links from the G8 (\%)

\begin{tabular}{|l|l|l|l|l|l|l|l|l|l|l|}
\hline Country & US & Canada & UK & France & Japan & Germany & Russia & Italy & China & Total \\
\hline Benin & 0.03 & 0.01 & 0.01 & 0.01 & 0.01 & 0.01 & 0.01 & 0.01 & 0.01 & 0.04 \\
\hline Cameroon & 0.32 & 0.01 & 0.01 & 0.01 & 0.01 & 0.01 & 0.01 & 0.01 & 0.01 & 0.34 \\
\hline Cape Verde & 0.09 & 0.01 & 0.01 & 0.01 & 0.02 & 0.01 & 0.01 & 0.01 & 0.01 & 0.11 \\
\hline Congo & 0.02 & 0.01 & 0.01 & 0.01 & 0.01 & 0.01 & 0.01 & 0.01 & 0.01 & 0.02 \\
\hline Egypt & 2.45 & 0.02 & 0.00 & 0.01 & 0.01 & 0.03 & 0.01 & 0.01 & 0.01 & 2.55 \\
\hline Gabon & 0.07 & 0.01 & 0.01 & 0.01 & 0.01 & 0.01 & 0.01 & 0.01 & 0.01 & 0.07 \\
\hline Kenya & 1.33 & 0.01 & 0.08 & 0.01 & 0.01 & 0.02 & 0.01 & 0.01 & 0.01 & 1.47 \\
\hline Morocco & 1.91 & 0.03 & 0.12 & 0.08 & 0.03 & 0.04 & 0.01 & 0.01 & 0.01 & 2.25 \\
\hline Nigeria & 0.42 & 0.01 & 0.03 & 0.01 & 0.01 & 0.01 & 0.01 & 0.01 & 0.01 & 0.48 \\
\hline Seychelles & 1.95 & 0.01 & 0.04 & 0.01 & 0.00 & 0.02 & 0.01 & 0.01 & 0.02 & 2.06 \\
\hline South Africa & 81.54 & 3.32 & 2.47 & 0.17 & 0.26 & 0.01 & 0.16 & 0.01 & 0.01 & 87.96 \\
\hline Sudan & 0.07 & 0.01 & 0.02 & 0.01 & 0.01 & 0.01 & 0.01 & 0.01 & 0.01 & 0.10 \\
\hline Tunisia & 0.51 & 0.01 & 0.01 & 0.02 & 0.01 & 0.01 & 0.01 & 0.01 & 0.01 & 0.56 \\
\hline Zambia & 0.53 & 0.01 & 0.02 & 0.01 & 0.00 & 0.01 & 0.01 & 0.01 & 0.01 & 0.57 \\
\hline Zimbabwe & 1.12 & 0.01 & 0.26 & 0.01 & 0.01 & 0.01 & 0.01 & 0.01 & 0.01 & 1.42 \\
\hline Total & $\mathbf{9 2 . 3 7}$ & $\mathbf{3 . 4 2}$ & $\mathbf{3 . 0 8}$ & $\mathbf{0 . 2 9}$ & $\mathbf{0 . 3 3}$ & $\mathbf{0 . 1 7}$ & $\mathbf{0 . 2 1}$ & $\mathbf{0 . 0 8}$ & $\mathbf{0 . 0 5}$ & $\mathbf{1 0 0}$ \\
\hline
\end{tabular}

The distribution of external inlinks from each of the G8 and China to specific African countries can also be gleaned from Table 9. Apart from having the highest percentage of links to the region, the United States has percentage of links to any country in the region than any of the other G8 country. Except UK and Japan which had zero links to Egypt and Seychelles, other G8 countries including China consistently linked all the fifteen countries in our study.

\section{Web Impact of the links}

The web impact factor of the links was calculated using the formula:

Web impact factor $=$ Number of links

Number of pages

Table 10 Web impact of Africa

\begin{tabular}{|l|l|l|l|}
\hline Country & Overall WIF & Self-inlink WIF & External inlink WIF \\
\hline Benin & 0.50 & 0.10 & 0.50 \\
\hline Cameroon & 0.92 & 0.08 & 2.08 \\
\hline Cape Verde & 0.15 & 0.08 & 0.06 \\
\hline Congo & 0.52 & 0.17 & 0.31 \\
\hline Egypt & 0.19 & 0.08 & 0.11 \\
\hline Gabon & 0.21 & 0.09 & 0.10 \\
\hline Kenya & 0.26 & 0.09 & 0.16 \\
\hline Morocco & 0.25 & 0.09 & 0.15 \\
\hline Nigeria & 0.20 & 0.10 & 0.09 \\
\hline Seychelles & 0.62 & 0.07 & 0.54 \\
\hline South Africa & 0.21 & 0.09 & 0.86 \\
\hline Sudan & 0.21 & 0.09 & 0.11 \\
\hline Tunisia & 0.17 & 0.09 & 0.09 \\
\hline Zambia & 0.20 & 0.09 & 0.09 \\
\hline Zimbabwe & 0.32 & 0.09 & 0.21 \\
\hline Overall & $\mathbf{0 . 2 2}$ & $\mathbf{0 . 0 9}$ & $\mathbf{0 . 7 3}$ \\
\hline
\end{tabular}


The overall web impact factor for Africa is 0.25 . For the fifteen countries in the study, the overall web impact factor $=$ 0.22 , self web impact factor $=0.09$ and external web impact factor $=0.73$. Table 10 shows the detail for each of the countries. Cameroon has the highest overall impact factor while Cape Verde has the least.

Self-inlink impact factor is generally very low among the countries, but is highest with Congo while the least is Seychelles. On its own part, external inlink impact factor is highest with Cameroon while the least externally inlinked is Cape Verde. At the sub-regional levels, the central region has the highest impact factor 0.536 while the north had the lowest impact factor 0.213 . the figures for eastern, south and west were $0.310,0.218$ and 0.323 respectively.

\subsection{Some statistical analysis}

Using Spearman rank correlation analysis, bivariate correlation was sought between pairs of population, Internet users in the countries, web pages, inlinks, self-inlinks, educational inlinks, government inlinks, organizational inlinks, educational self-inlinks, government self-inlinks, organisational self-inlinks, African inlinks and Internet penetration. The lowest correlations are between penetration and population (0.02), penetration and educational links $(0.029)$, and, penetration and educational links (0.09).

Also, population has a low correlation with number of web pages and with self-inlinks; Internet users also has a similar correlation with educational self-inlinks just as self-inlinks with educational inlinks and educational self links. All other correlations are above 0.5 . But it is significant that Internet users and population, inlinks and web pages, links from Africa to other African countries and web pages, inlinks and organisational inlinks, organisational self-inlinks and government inlinks have very high correlations. Inlinks to a country in Africa from all sources and total number of inlinks from countries in Africa to any African country shows a significant and high correlation. self-inlinks have low correlations with population and with number of Internet users, and also with educational inlinks as well as and educational self-inlinks. Correlation between self-inlinks and other variables is high. Correlations between educational inlinks, governmental inlinks, organizational inlinks, educational self-inlinks, governmental self-inlinks, organizational self-inlinks and Africa inlinks, and any other variable are high.

Table II Some correlation analysis

\begin{tabular}{|c|c|c|c|c|c|c|c|c|c|c|c|c|c|}
\hline & $\begin{array}{c}\text { Popu- } \\
\text { lation }\end{array}$ & $\begin{array}{c}\text { Internet } \\
\text { users }\end{array}$ & $\begin{array}{c}\text { Web } \\
\text { pages }\end{array}$ & Inlinks & $\begin{array}{c}\text { Self } \\
\text { Links }\end{array}$ & $\begin{array}{c}\text { Edu. } \\
\text { Inlinks }\end{array}$ & $\begin{array}{c}\text { Gov. } \\
\text { inlinks }\end{array}$ & $\begin{array}{c}\text { Org. } \\
\text { inlinks }\end{array}$ & $\begin{array}{c}\text { Edu. } \\
\text { self- } \\
\text { inlinks }\end{array}$ & $\begin{array}{c}\text { Gov. } \\
\text { self- } \\
\text { inlinks }\end{array}$ & $\begin{array}{c}\text { Org. } \\
\text { self- } \\
\text { inlinks }\end{array}$ & $\begin{array}{c}\text { Africa } \\
\text { Inlinks }\end{array}$ & $\begin{array}{l}\text { Penetration } \\
\text { 1 }\end{array} 1.000$ \\
\hline 2 & & 1.91 & 0.48 & 0.53 & 0.44 & 0.70 & 0.81 & 0.67 & 0.69 & 0.83 & 0.66 & 0.52 & 0.016 \\
\hline 3 & & & 1.00 & 0.91 & 0.79 & 0.71 & 0.79 & 0.77 & 0.64 & 0.79 & 0.78 & 0.91 & 0.556 \\
\hline 4 & & & & 1.000 & 0.79 & 0.59 & 0.87 & 0.90 & 0.52 & 0.83 & 0.88 & 0.59 & 0.615 \\
\hline 5 & & & & & 1.00 & 0.48 & 0.73 & 0.73 & 0.44 & 0.71 & 0.75 & 0.78 & 0.567 \\
\hline 6 & & & & & & 1.00 & 0.66 & 0.55 & 0.99 & 0.70 & 0.56 & 0.58 & 0.091 \\
\hline 7 & & & & & & & 1.00 & 0.96 & 0.62 & 0.98 & 0.96 & 0.86 & 0.433 \\
\hline 8 & & & & & & & & 1.00 & 0.52 & 0.92 & 0.99 & 0.90 & 0.549 \\
\hline 9 & & & & & & & & & 1.000 & 0.66 & 0.52 & 0.52 & 0.029 \\
\hline 10 & & & & & & & & & & 1.00 & 0.93 & 0.83 & 0.384 \\
\hline 11 & & & & & & & & & & & 1.000 & 0.88 & 0.533 \\
\hline 12 & & & & & & & & & & & & 1.00 & 0.615 \\
\hline 13 & & & & & & & & & & & & & 1.000 \\
\hline
\end{tabular}

\section{Discussion of results}

Miniwatts Marketing Group (2008) reported that 3.5\% of Africans had access to the Internet as at 2008, and that the continent achieved a penetration of 4.7. Our study shows that the top 15 countries achieved a penetration of 8.28 and about $9 \%$ of users. These figures could still be considered very low, considering that the countries where web pages or inlinks were either not discernible or very low such as Western Sahara, Mayotte, Somalia, Chad and Guinea Bissau were excluded from the study. Seychelles, Morocco, Tunisia and South Africa have the highest penetration, achieving a penetration greater than 10, while Congo and Cameroon have the least. In terms of proportion of Internet users, Nigeria, Morocco, Egypt and South Africa topped other countries, while Cape Verde, Seychelles, Congo, Gabon and Zambia have less than one percent of their populations using the Internet. The western sub-region has the highest number of Internet users, while the central has the lowest number of Internet users and the lowest penetration; the east and north have the highest penetration. 
South Africa accounts for a major proportion of web pages produced in Africa, posting almost five web pages for each web page developed in the whole of the region. Although most of the countries in the sample are French speaking, the English-speaking countries led mainly by South Africa accounts for much of the web pages in the region. At the sltd level, organizational pages accounted for much of the web pages, followed by governmental web pages. Ironically, educational web pages are the least in volume, and many of them come from South Africa. Benin, Cameroon, Gabon and Tunisia, all French speaking countries, did not provide any educational pages; all countries except Congo had governmental web pages. Cape Verde, Zambia, Seychelles, Cameroon and Gabon had no organizational web pages.

South Africa has such as huge number of web pages that outstrips its population by more than 900 times. South Africa also has a huge number of organizational pages per population, probably signifying a high level of deployment of the infrastructure for organizational activities. Zimbabwe, South Africa and to a lesser extent Congo have higher inlinks from other African countries than the inlinks they made to other African countries. Although all the countries received inlinks to their web pages, South Africa also dominated the inlinks to the region accounting for more than $82 \%$ of the whole, and this is the situation at educational, governmental and organizational domain levels. Organizational inlinks outnumbered both educational and governmental inlinks. The study showed that countries from the southern sub-region have higher number of links to countries close to them compared to countries from the west region which have very few links to countries from the same subregion. The study also showed that the education sub-domain has a higher number of links originating and terminating in the same domain than the two other sub-domains while the government sub-domain had the least number of self-inlinks. The governments probably create web pages in anticipation that other people than the government would use them.

The study also investigated the nature of inlinks to African countries from other African countries. Comparing the total self-inlinks with the links to the individual countries from African countries only shows that African countries seldom link other African countries as much as each country links itself. By implication, electronic information produced by African countries are seldom consumed by countries in Africa, except, to some extent, by the individual countries creating the links. South Africa and Zimbabwe appear to be exceptions to this observation being major recipients of inlinks from other African countries. Kenya and South Africa also stand out somehow, because they made substantial inlinks to other African countries more than the other countries. In terms of consistency in inlinks, Nigeria and South Africa were the only countries that received inlinks from all the countries in the study, although the volume of inlinks to Nigeria is by far less than that of South Africa. Generally African countries made inlinks to other African countries more than they received from other African countries.

On the inlinks from the G8 and China, US inlinked the region and the individual countries the most; but a huge proportion of these links go to South Africa. Inlinks from the G8 countries are, by far, higher than inlinks to African countries from other African countries. A significant inference from this result is the possibility that African information may achieve a very wide patronage if the information is adequately organized and marketed.

Generally, Africa has fractional web impact factors, a result that has implication that the web pages produced by Africa are either redundant or hardly ever accessed by anyone. By further implication, the information contained in the pages are not accessed and used by those for whom they are created. This result corroborates Nwagwu and Agarin (2006) which showed in a study on web link analysis of Nigerian universities that the universities do not link themselves, and are also seldom linked by anyone at all. This situation is repeated at country levels, except that Congo appears to be more inward looking in terms of self-inlinks than the other countries. The first four countries with the highest overall impact factors: Cameroon, Seychelles and Congo, and the two with highest self inlink impact factors: Congo and Benin are French speaking, while the highest external impact factor is recorded by bilingual Cameroon. Generally the low web impact has great significance in view of several observations and projects aimed at enhancing South-North information flow (Nwagwu, 2008; Arunachallam, 2007). the low impact factors suggest low iluse of the web re4sources created by African countries.

The correlation analysis shows that large population does not necessarily result to a large number of web pages, selfinlinks, and inlinks from African countries or penetration. A country with large population, for instance, will not necessarily be guaranteed of the Internet users in that country creating web pages of their own or linking web pages created in their countries. In the same way a large size of Internet users in a country will not suggest that the users use the Internet for educational purposes neither does heavy self-linking necessarily suggest that linkers are using the facility for educational purposes.

However, there is high likelihood that higher population will lead to higher number of Internet users. The low correlation between educational links and number of Internet users might imply that high number of Internet users does not amount to use of the Internet for educational purposes, or production of educational information. Number of

SA Jnl Libs \& Info Sci 2010, 76(2) 
Internet users also has a low correlation with penetration, because Internet users relate to absolute number of persons using the Internet whereas penetration relates this number to the population of the country.

Generally our result suggests low web page creation and low use of the resources in the web pages that are created. The low or non-use of African pages raises several issues? For instance, Nwagwu (2008) has suggested that merely embarking on projects that put African information online will not guarantee that the information will be used by anyone, not even by people at home. There is need therefore to examine reasons for non-use of African electronic information, including quality of resources that are deposited in the websites and the content of the websites. It is also appropriate for scholars to start engaging on studies that address the nature of the new forms of digital divide engendered by the use characteristics of the Internet in view of many speculations that Internet may immense benefit the developing regions are expected to reap from the infrastructure. It is also appropriate to start examining how Africans, their countries and institutions themselves account for the low status accorded to the region in international information production and the pattern of information creation and consumption in the web. The high correlation between inlinks to a African country from all sources and the total number of inlinks from countries in Africa would suggest that African countries that are inlinked by other African counties are most likely to also be inlinked by other than African countries.

\section{References}

Boldi, P.; Codenotti, B.; Santini, M \& Vigna, S. 2002. Structural properties of the African web. In Proceedings of the /Ith International World Wide Web Conference. Honolulu, Hawaii.

Goodrum, AA.; McCain, KW.; Lawrence, S. \& Giles, CL. 200I. Scholarly publishing in the Internet age: a citation analysis of computer science literature. Information Processing and Management, 37(5), 66I-76.

Halliday, L., \& Oppenheim, C. 200I. Developments in digital journals. Journal of Documentation, 57(2), 260-83.

Miniwatts Marketing Group. 2008. [Online]. http://www.miniwatts.com/. (accessed 10 December 2008).

Nwagwu, WE \& Agarin, O. 2007. A webometric analysis of Nigerian universities' Websites. Ibadan Journal of the Social Sciences $5(1), 43-54$.

Onyancha, OB \& Ocholla, DN. 2006. Web presence and impact of South African universities: a cybermetric study. [Online]. http://www.lis.uzulu.ac.za/2006/Onyancha\&Ocholla_DLIS_ConferenceSept2006.pdf. (Accessed 2 February 2008).

Onyancha, OB \& Ocholla, DN. 2007. The performance of South African and Kenyan universities on the World Wide Web: a Web link analysis. Cybermetrics, II (I). [Online]. www.cindoc.csic.es/cybermetrics/articles/vl lilp2.pdf. (Accessed 2 December 2007).

Spink, A \& Jansen, B. 2004. Webology I (2). A study of Web search trends. [Online]. http://webology.ir/2004/v/n2/a4.html. (Access 10 April 2010).

Town, WG.., Vickery, BA., Kuras, J \& Weekes, JR. 2002. Chemical e-journals, chemical e-prints. Online Information Review, 26(3): |64-7|. 